\title{
A multiperiod location-routing problem arising in the collection of olive oil mill wastewater
}

\begin{abstract}
The process by which olive oil is produced yields two by-products, one of which is the brown coloured Olive Oil Mill Wastewater (OMWW) and has no direct use. OMWW is generally disposed of into soil or rivers, potentially contaminating the environment. OMWW can be treated using ultrafiltration facilities, but this requires that OMWW is collected from oil mills and delivered to the treatment facilities using a fleet of vehicles in an economically viable manner. Such considerations give rise to a multiperiod locationrouting problem. This paper formally introduces the problem and proposes an adaptive large neighbourhood search metaheuristic for its solution. The algorithm is applied on a case study drawn from one of the major olive oil producing countries. The paper presents computational and managerial results.

Keywords: location-routing problem; olive oil mill wastewater; environmental hazards; treatment; adaptive large neighbourhood metaheuristic.
\end{abstract}

\section{Introduction}

Olive is grown in nearly 42 countries in the Mediterranean and in other countries with a similar climate (FAO, 2015). Some European Union (EU) countries such as Spain, Italy, Greece, Portugal and France are significant producers of olive oil, the total amount of which accounts for $60 \%$ of the global olive production, $40 \%$ of the global table olive production and $80 \%$ of the global olive oil production. Tunisia, Turkey, Egypt and Syria are other important olive producing countries. Adoption of healthier diets in many parts of the world has resulted in an increased interest in the the Mediterranean diet, which includes consumption of olives and olive oil.

Olive is processed into table or olive oil in olive mills using various production technologies. There are a number of ways of extracting olive oil, ranging from the more traditional (classical) techniques that use presses, to the more modern two- and three-phase systems. The modern methods are based on principles of malaxation, decantation, centrifugation and percolation, and combinations thereof. Countries with a significant olive production use the modern systems to extract oil. For example, while Spain uses a twophase system, Greece and Italy in general have a three-phase system in place. The process through which 
olive oil is produced yields a number of by-products that are potentially harmful to the environment. One of these by-products is pomace, which can be re-processed as oil and used as raw material in various sectors, such as food, industrial and energy. The other by-product is the Olive Oil Mill Wastewater (OMWW). The composition of OMWW varies with respect to the system it is produced through, but generally consists of water (83-92\%) that is used as input to the various stages of olive oil production systems, organic matter (4-16\%) and minerals (1-2\%). OMWW has high salinity and low acidity and is rich in organic matters such as N, P, K and Mg. Despite this, however, the OMWW is not yet considered to be usable unless treated.

Uncontrolled and direct use of OMWW on land (e.g., as often done in irrigation) is undesirable due to its highly phytotoxic content, which may have detrimental effects on soil microbial populations (Paredes et al., 1987; Roig et al., 2006). Evidence suggests that long-term and intensive use of OMWW for irrigation would leave fields prone to groundwater contamination (Mahmoud et al., 2010). Discharging OMWW into the sea, either directly or indirectly, is also not an option given the risks around water pollution and threats to the aquatic life (Akdemir and Ozer, 2008).

Several alternative schemes have been suggested and are in use for dealing with OMWW, which are detailed below:

1. A traditional and conventional method is the use of lagoons (see Figure 1 for an example) in which OMWW is kept until it naturally evaporates. This method is particularly applicable in countries with a sufficiently warm climate to allow for natural evaporation. However, this is not an efficient or desirable method for several reasons. The first is the obvious space requirements. Second, when kept in a reserve for prolonged periods of time, OMWW would potentially lead to ground contamination unless the lagoon is not designed properly. Further problems with increasing odour and rapid breeding of insects around the lagoon would also lead to an unhygienic environment (Azbar et al., 2004).

2. Another option is to consider the use of integrated olive mills (Azbar et al., 2004) wherein facilities exist for performing olive oil extraction and wastewater treatment in an integrated and a sequential manner. The cost of establishing such facilities is usually very significant and unlikely to be adopted unless funding is made available by governments, private institutions or unions.

3. There are several ways in which OMWW can be treated. One way is physico-chemical, which uses flocculation, coagulation, filtration and incineration. Another way is bio-technological, which includes microbiological treatments, composting, anaerobic and extraction processes (Roig et al., 2006). Akdemir and Ozer (2008) state that the treatment of OMWW through such methods has, to date, not been entirely successful, and suggest ultrafiltration as a viable alternative to those already mentioned. 


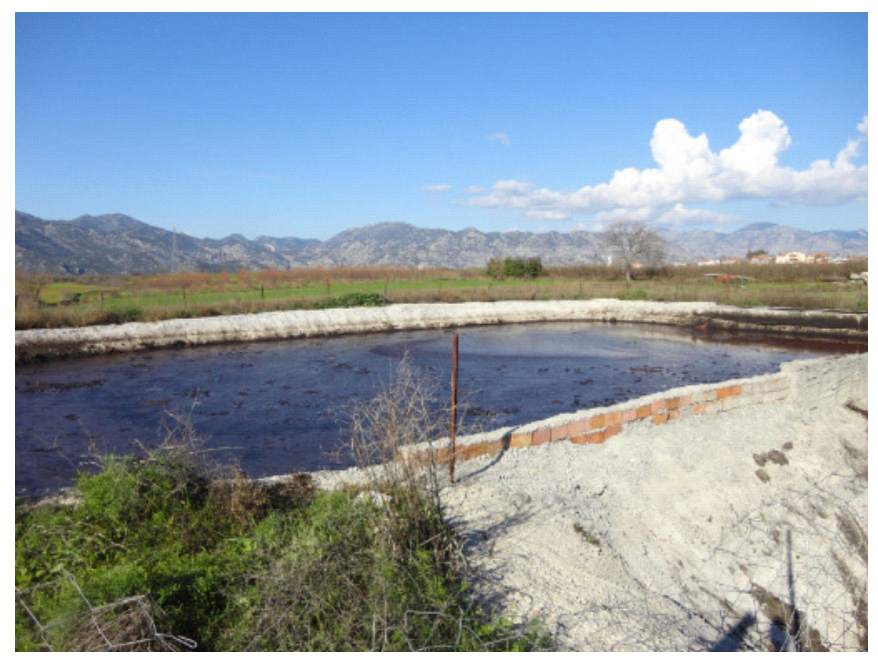

Figure 1: An example of a lagoon

A number of business models for waste water reuse have been developed and shown to be promising in the past (see, e.g., Axelrad and Feinerman, 2009), which envisage the construction of a number of ultrafiltration (or treatment) facilities to serve several olive oil mills in a given geographic region. Libralato et al. (2012) discuss the role of centralisation versus decentralisation in wastewater treatment and point out that the wastewater treatment cost per unit volume is still competitive in the former as compared to the latter.

This last option mentioned above, namely the use of treatment facilities, which forms the basis of and the motivation behind the proposed approach in the paper. In particular, we study and solve a planning problem in which ultrafiltration facilities are built for treatment of OMWW, and the collection operates using a fleet of vehicles that operate on a regular basis over a given period.

Facility location and vehicle routing are two interdependent decisions. The joint study of these two problems was first suggested by Von Boventer (1961) and has now evolved into what is now commonly known as the Location-Routing Problem (LRP) (see Laporte, 1988; Nagy and Salhi, 2007; Prodhon and Prins, 2014; Albareda-Sambola, 2015; Drexl and Schneider, 2015, for reviews). The LRP assumes a single period of planning. Studies on the multiperiod version of the LRP are few and far between. One of these, namely the Multiperiod LRP with Decoupled Time Scales is studied by Albareda-Sambola et al. (2012) in which a discrete facility location problem is defined over a finite time horizon, and in which location and routing decisions are made over different time scales. In particular, their setting allows facility decisions to be made over a predefined subset of periods in the time horizon. The authors developed an approximation to solve the problem without losing the capability of finding well located facilities with the sets of customers along 
the time horizon. The problem studied here is a particular case of Albareda-Sambola et al. (2012) in that we assume all facility decisions are only made once, at the beginning of the planning horizon, and no further locations decisions are to be made at any point in the time horizon. In addition, we include constraints on the capacity of each facility, which are to be selected from a finite set of capacity levels, and are to be decided jointly with the location decisions.

Our problem is also relevant to waste collection vehicle routing problems, which have been studied in the literature (e.g., Kim et al., 2006; Benjamin and Beasley, 2010). Some examples are the hazardous waste transportation and disposal problem (Zografros, 1989), the hazardous waste LRP (Alumur and Kara, 2007), locating treatment sites and routing hazardous waste (Giannikos, 1998), and industrial hazardous waste LRP (Samanlioglu, 2013). However, the multiperiod nature of the problem that we address, to the best of our knowledge, does not seem to have been considered in the previous literature. In particular, all the papers cited above assume that the routing decisions are taken on the basis of a single time period (e.g., day), and do not incorporate the possibility that collections might be made on different days for different customers. In this sense, our problem resonates with the periodic vehicle routing problem (e.g., Hemmelmayr et al., 2009), with the exception that the visit days in our study are decided by the decision maker, as opposed to being imposed by the customers.

This paper is therefore concerned with the joint multiperiod problem of locating ultrafiltration facilities and routing decisions for the collection and treatment of OMWW. It makes three main scientific contributions. Our first contribution is to define and formulate the problem. Our second contribution is describe an Adaptive Large Neighbourhood Search (ALNS) metaheuristic to solve the problem, which allows us to carry out computational experiments and analyses. Our third contribution is to provide several managerial insights by exploring the effects of the various parameters of the problem.

The remainder of this paper is structured as follows. The next section provides a description of the problem and a mathematical programming formulation. The subsequent section contains a description of the proposed metaheuristic. The penultimate section presents a case study and the solutions we propose. The last section presents the conclusions.

\section{Formal Problem Definition and Mathematical Formulation}

The problem is defined on a directed graph $\mathcal{G}=(\mathcal{N}, \mathcal{A})$, where $\mathcal{N}=\mathcal{N}_{0} \cup \mathcal{N}_{c}$ is a set of nodes, and $\mathcal{N}_{0}$ and $\mathcal{N}_{c}$ represent the locations of the potential treatment facilities and olive oil mills, respectively. The arc set $\mathcal{A}$ 
is defined as $\{(i, j): i \in \mathcal{N}, j \in \mathcal{N}\} \backslash\left\{(i, j): i \in \mathcal{N}_{0}, j \in \mathcal{N}_{0}, i \neq j\right\}$. In other words, no arcs exist between the potential treatment facilities. The physical distance from an olive mill $i \in \mathcal{N}_{c}$ to a potential treatment facility location $j \in \mathcal{N}_{0}$ is shown by $c_{i j}$. There is a unit cost (e.g., $€ /$ ton kilometers) of transporting the OMWW shown by $\delta$. We assume that each olive mill $i \in \mathcal{N}_{c}$ has a fixed production capacity $\hat{q}_{i}$ that can be stated in daily, weekly or monthly units, which translates into an OMWW output rate. Each treatment facility can operate at a certain capacity level in a set $\mathcal{S}$, where each level $s \in \mathcal{S}$ represents the amount of treatment capacity of $b_{s}$ units (e.g., volume) per unit of time. Similar to olive mills, this capacity can be stated in terms of days or weeks. In our modelling, we use the former. We therefore associate a storage capacity $b_{k}^{s}$ and a fixed opening $\operatorname{cost} g_{k}^{s}$ to a potential $\operatorname{depot} k \in \mathcal{N}_{0}$ and capacity level $s \in \mathcal{S}$. In addition to working capacity, treatment facilities are designed to hold a certain amount of working stock, and this is normally five times the capacity of its processing capacity. For example, a treatment facility that can process $100 \mathrm{~m}^{3}$ tonnes of OMWW a day can hold up to $500 \mathrm{~m}^{3}$ of OMWW in its reserves to be processed later on. Olive mills can usually hold OMWW for several days, but the total time should not exceed seven days from the time that OMWW is first brought in. Longer periods would result in contamination and cause odours. Bearing this in mind, our design proposal considers a planning horizon of one week, the plan of which would repeat itself every week. The planning horizon is divided into days that are indexed in set $\mathcal{H}=\{1,2, \ldots, 7\}$.

We assume an unlimited and homogeneous vehicles available for collection, each with an OMWW transportation capacity of $Q$ tonnes. The number of vehicles needed for a particular day can be calculated by $\left\lceil\sum_{i \in \mathcal{N}_{c}} \hat{q}_{i} / Q\right\rceil$. In the event that $\hat{q}_{i}>Q$ for a given $i \in \mathcal{N}_{c}$, i.e., the amount of OMWW produced at a particular mill exceeds that of a given vehicle capacity $Q$, one can allocate $\left\lceil\left(\hat{q}_{i}-\hat{q}_{i} \bmod Q\right) / Q\right\rceil$ many dedicated vehicles to this mill a priori, in which case the transportation will be done in full vehicle load. One can then only consider the "excess" $q_{i}=\hat{q}_{i} \bmod Q$ units of OMWW in the planning.

To formulate the problem, we define the following decision variables. Let $x_{i j}^{h}$ be a binary variable equal to 1 if a vehicle travels on $\operatorname{arc}(i, j) \in \mathcal{A}$ on day $h \in \mathcal{H}$, and 0 otherwise. A second set of binary variables represent the location decisions, namely $y_{k}^{s}$ that is equal to 1 if a treatment facility on node $k \in \mathcal{N}_{0}$ is established at level $s \in \mathcal{S}$, and 0 otherwise. The third set of binary variables are olive mill-vehicle assignments, where $z_{i k}^{h}$ is equal to 1 if olive mill $i \in \mathcal{N}_{c}$ served by a vehicle leaving depot $k \in \mathcal{N}_{0}$ on day $h \in \mathcal{H}$, and to 0 otherwise. The last set of binary variables indicate the day assignments, in particular $v_{i}^{h}$ is equal to 1 if olive mill $i \in \mathcal{N}_{c}$ is visited on day $h \in \mathcal{H}$ and to 0 otherwise. Finally, a continuous variable $u_{i j}^{h}$ defines the total load of a vehicle immediately after visiting node $i \in \mathcal{N}$ and travelling to node $j \in \mathcal{N}$ on day $h \in \mathcal{H}$.

An interesting feature of the problem is the varying amount of collection from a mill $i \in \mathcal{N}_{c}$ on a given 
day $h \in \mathcal{H}$, which depends on whether any collection is made previously. In more formal terms, the total amount to be collected from $i \in \mathcal{N}_{c}$ on a day $h \in \mathcal{H}$ is $h q_{i}$ and any previous collections can be shown by $\sum_{d=0}^{h-1} d q_{i}$. Using the variable $v_{i}^{h}$ to denote the collection, the amount of OMWW to be collected on day $h$ is shown by $h q_{i} v_{i}^{h}-\sum_{d=0}^{h-1} d q_{i} v_{i}^{d}$.

The problem consists of opening a number of treatment facilities that will serve to treat OMWW produced by all the mills in a particular geographic area. Each treatment facility have a fleet of vehicles at its disposal to collect OMWW from a number of mills every day, implying that all vehicles that start their routes from a treatment facility, will have to return to the same facility, and the load of each vehicle does not exceed its capacity. The decisions of routing the vehicles lie at the operational level of decision making. Each vehicle has a limited capacity to hold the wastewater. The objective is to minimise the total cost of treatment facility set-up and the total transportation costs. The mathematical formulation of the problem is given as follows:

$$
\text { Minimise } \sum_{s \in \mathcal{S}} \sum_{k \in \mathcal{N}_{0}} g_{k}^{s} y_{k}^{s}+\sum_{h \in \mathcal{H}} \sum_{(i, j) \in \mathcal{A}} c_{i j} x_{i j}^{h}
$$

subject to

$$
\begin{array}{rl}
\sum_{h \in \mathcal{H}} \sum_{j \in \mathcal{N}} x_{i j}^{h} \geq 1 & i \in \mathcal{N}_{c} \\
\sum_{j \in \mathcal{N}} x_{j i}^{h}=\sum_{j \in \mathcal{N}} x_{i j}^{h} & i \in \mathcal{N}, h \in \mathcal{H} \\
\sum_{j \in \mathcal{N}} u_{i j}^{h}-\sum_{j \in \mathcal{N}} u_{j i}^{h}=h q_{i} v_{i}^{h}-\sum_{d=0}^{h-1} d q_{i} v_{i}^{d} \quad & i \in \mathcal{N}_{c}, h \in \mathcal{H} \\
u_{i j}^{h} \leq Q x_{i j}^{h} & i \in \mathcal{N}, j \in \mathcal{N}_{0}, i \neq j, h \in \mathcal{H} \\
\sum_{j \in \mathcal{N}_{c}} u_{j k}^{h}=\sum_{j \in \mathcal{N}_{c}} z_{j k}^{h}\left(h q_{j} v_{j}^{h}-\sum_{d=0}^{h-1} d q_{j} v_{j}^{d}\right) & k \in \mathcal{N}_{0}, h \in \mathcal{H} \\
\sum_{j \in \mathcal{N}_{c}} u_{k j}^{h}=0 & k \in \mathcal{N}_{0}, h \in \mathcal{H} \\
u_{i j}^{h} \leq\left(Q-\left(h q_{j} v_{j}^{h}-\sum_{d=0}^{h-1} d q_{j} v_{j}^{d}\right)\right) x_{i j}^{h} & i \in \mathcal{N}_{c}, j \in \mathcal{N}, i \neq j, h \in \mathcal{H} \\
u_{i j}^{h} \geq\left(h q_{i} v_{i}^{h}-\sum_{d=0}^{h-1} d q_{i} v_{i}^{d}\right) x_{i j}^{h} & i \in \mathcal{N}, j \in \mathcal{N}_{c}, i \neq j, h \in \mathcal{H} \\
\sum_{i \in \mathcal{N}_{c}}\left(h q_{i} v_{i}^{h}-\sum_{d=0}^{h-1} d q_{i} v_{i}^{d}\right) z_{i k}^{h} \leq \sum_{s \in \mathcal{S}} b_{k}^{s} y_{k}^{s} & k \in \mathcal{N}_{0}, h \in \mathcal{H} \\
\sum_{h \in \mathcal{H}} \sum_{k \in \mathcal{N}_{0}} \sum_{j \in \mathcal{N}_{c}} u_{j k}^{h}=|\mathcal{H}| \sum_{i \in \mathcal{N}_{c}} q_{i} &
\end{array}
$$




$$
\begin{array}{rlrl}
\sum_{k \in \mathcal{N}_{0}} z_{i k}^{h}=v_{i}^{h} & & i \in \mathcal{N}_{c}, h \in \mathcal{H} \\
x_{i k}^{h} \leq z_{i k}^{h} & & k \in \mathcal{N}_{0}, i \in \mathcal{N}_{c}, h \in \mathcal{H} \\
x_{k i}^{h} \leq z_{i k}^{h} & & k \in \mathcal{N}_{0}, i \in \mathcal{N}_{c}, h \in \mathcal{H} \\
x_{i j}^{h}+z_{i k}^{h}+\sum_{m \in \mathcal{N}_{0}, m \neq k} z_{j m}^{h} \leq 2 & & k \in \mathcal{N}_{0},(i, j) \in \mathcal{N}_{c}, i \neq j, h \in \mathcal{H} \\
x_{i j}^{h} & \in\{0,1\} & & (i, j) \in \mathcal{N}, h \in \mathcal{H} \\
z_{i k} & \in\{0,1\} & k \in \mathcal{N}_{0}, i \in \mathcal{N}_{c} \\
y_{k} \in\{0,1\} & k \in \mathcal{N}_{0} \\
v_{i}^{h} \in\{0,1\} & i \in \mathcal{N}, h \in \mathcal{H} \\
u_{i j}^{h} \geq 0 & (i, j) \in \mathcal{N}, h \in \mathcal{H} .
\end{array}
$$

The objective function (1) minimises the total cost including depot fixed cost and the variable travel cost. Constraints (2) guarantee that each olive mill must be visited at least once over the planning horizon, and constraints (3) ensure that the number of arcs entering and leaving each node on each day are equal. Constraints (4) imply that the total waste water from each mill is collected in full over the planning horizon. Vehicle capacity constraints are represented by constraints (5), which mean that the total load on any arc cannot exceed the capacity of the vehicle traversing it. Constraints (6) ensure that the total amount shipped to each facility is equal to the total OMWW output of the mills assigned to it on each day. Constraints (7) state that the load on a vehicle starting its tour from a facility must be equal to zero. The load on each vehicle can be bounded from below by at least the amount to be collected and from above by the remaining capacity left on the vehicle when it is travelling on an arc, which is modelled by constraints (8) and (9). Constraints (10) guarantee that total OMWW collected by a facility cannot exceed the capacity at which it is selected to operate. Constraints (11) ensure that total OMWW over the planning horizon is collected by the treatment facilities. Constraints (12) ensure that each customer is assigned to only one depot. Constraints (13)-(15) forbid illegal routes, i.e., routes that do not start and end at the same depot. Finally, constraints (16)-(20) define the integrality and non-negativity restrictions on the decision variables.

The formulation presented above is that of a multiperiod location-routing problem, which is hard to solve optimally as it requires the joint solution several difficult subproblems, including the facility location problem and the vehicle routing problem. In addition, constraints (6), (8), (9) and (10) are nonlinear due to the multiplication of binary variables. To overcome this barrier, we describe a metaheuristic in the next section. 


\section{An Adaptive Large Neighbourhood Search Metaheuristic}

In this section, we describe a metaheuristic for solving the problem described above, which we name as Multiperiodic-Adaptive Large Neighbourhood Search (MP-ALNS), is partly based on the ALNS put forward by Pisinger and Ropke (2007) to solve several variants of the Vehicle Routing Problem (VRP) (see Laporte et al., 2014). This metaheuristic and its variations have since provided very good results on complicated variants of the VRP (see Ropke and Pisinger, 2006a,b; Koç et al., 2015) and of the LRP (see Koç et al., 2016). Given its evidenced success, our methodology will also be based on this search paradigm.

Given a feasible initial solution, the MP-ALNS follows a two-step procedure: first removal and then insertion. In the first step, $n^{\prime}$ olive mills are iteratively removed by a chosen destroy operator and placed in a removal list, where $n^{\prime}$ lies in the interval $\left[b_{l}, b_{u}\right]$. In the second step, nodes from the removal list are iteratively inserted into a least-cost position of the destroyed solution using an insertion operator. An illustration of the removal and insertion procedures are illustrated in Figure 2, for a problem instance with 10 olive mills shown by the circles and two treatment facilities in operation.

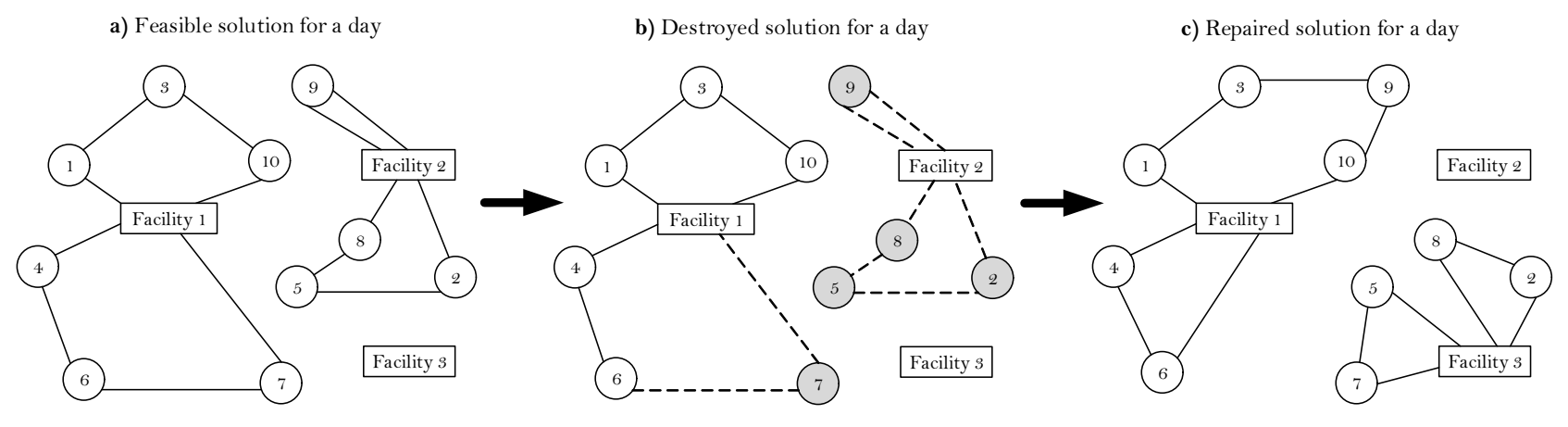

Figure 2: An illustration of the removal and insertion procedures

We dynamically select the operators according to their past performance. Each operator is assigned a score which is increased whenever it improves the current solution and is periodically reset to one. We use simulated annealing as an outer local search framework in order to define the acceptance rules of candidate solutions. We develop and test three versions of the MP-ALNS to effectively solve the problem, namely

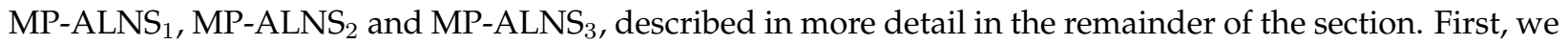
present a general description of the MP-ALNS in Algorithm 1, on which the three variants are based.

We now explain the steps of Algorithm 1. For the first day of the week, an initial solution $\omega_{0}$ for a given day is generated by using the procedure described in Koç et al. (2016). This feasible solution is then iteratively copied to remaining six days (line 1). The selection probabilities are initialised for each destroy and repair 


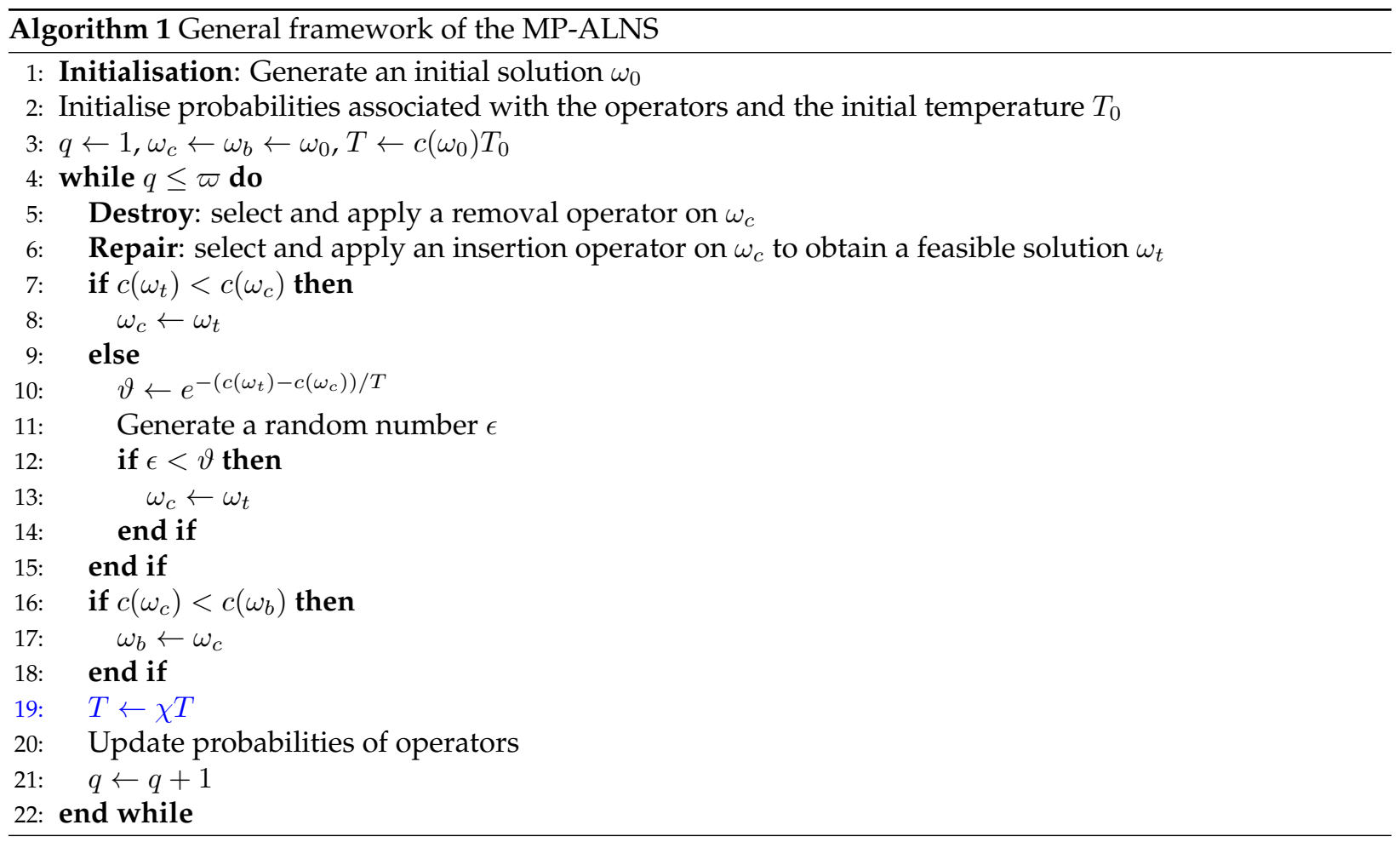

operator (line 2). In line 3, $\omega_{c}$ is the current solution obtained at the beginning of an iteration, $\omega_{b}$ is the best solution found during the search, and $\omega_{t}$ is a temporary solution found at the end of the iteration which either becomes the current solution or is discarded. The simulated annealing parameter $T$ denotes the temperature, initially set at $c\left(\omega_{0}\right) T_{0}$, where $c\left(\omega_{0}\right)$ is the cost of initial solution and $T_{0}$ is the initial temperature. The iteration counter is denoted by $q$, and the current and the best solutions are initially set equal to each other. The maximum number of iterations is denoted by $\varpi$. At the beginning of every iteration, a removal operator is selected and applied to the current solution (line 5). An insertion operator is then selected and applied to the destroyed solution, following which a feasible solution $\omega_{t}$ is obtained (line 6). If the cost of solution $\omega_{t}$ is less than that of the current solution $c\left(\omega_{c}\right)$, then $\omega_{c}$ is replaced by $\omega_{t}$ (lines $\left.7-8\right)$. Otherwise, the probability $\vartheta$ of accepting a non-improving solution is computed (lines 9-10) as a function of the current temperature. A random number $\epsilon$ is then generated in the interval $[0,1]$ (line 11). If $\epsilon$ is less than $\vartheta$, then $\omega_{c}$ is replaced by $\omega_{t}$ (lines 12-14). If the cost of $\omega_{c}$ is less than that of $\omega_{b}, \omega_{b}$ is replaced by $\omega_{c}$ (lines 16-18). The current temperature is gradually decreased during the algorithm as $\chi T$ (line 19), where $0<\chi<1$ is a fixed cooling parameter. The probabilities are updated by means of an adaptive weight adjustment procedure (line 20). When the maximal number $\varpi$ iterations is reached, the algorithm terminates (line 22) and returns the best found solution. For further information on the operators and on other algorithmic details the reader is referred to Koç et al. (2015). We now describe the three variants of MP-ALNS below. 
- Version 1: MP-ALNS 1 : A natural but a naive way to solve the problem is to find a feasible LRP solution for a single day and to repeat this solution for other periods in the time horizon. MP-ALNS ${ }_{1}$ does exactly this. Although this procedure might not yield a cheapest cost solution for the problem, it provides a benchmark against which variants can be assessed. Furthermore, such a solution might be easier to operationalise as the vehicles repeat the same tours every day. In MP-ALNS ${ }_{1}$, we modify an initial solution by applying destroy and repair operators as illustrated in Figure 2. At the beginning of each iteration, we first select a destroy and an insertion operator. We then iteratively apply these operators to each day of the week. When this iterative procedure is finished, the cost of each day is calculated. We select the cheapest cost day, and copy this solution across to the six remaining days.

- Version 2: MP-ALNS ${ }_{2}$ : The second version is a variation of MP-ALNS ${ }_{1}$, wherein a new procedure called a "the multiperiodic removal and insertion" is applied. We now explain the steps of this procedure by using the example illustrated in Figure 3, where the first table (a) shows the amount of OMWW to be collected from five olive oil mills in each of the seven days, obtained by MP-ALNS . $_{\text {. }}$ The idea here is to change the allocations so that better routes can be constructed. In the first step, we first randomly select a day, called "removal day", and apply a destroy operator to remove a set of to be visited olive mills on this day. Figure 3.b, shows that "Day 2" has been selected as a removal day, and where mills 1 and 4 with OMWW output of 15 and 25 tonnes, respectively, have been removed from the collection schedule on this day. In the next step, we randomly select a day, called "insertion day", which has to come later than the removal day. In Figure 3.c shows that "Day 6" has been selected as an insertion day, to which have the amount of OMWW for olive oil mills 1 and 4 has been added. At the end of this process, no OMWW will be collected from olive oil mills 1 and 4 on "Day 2". Instead, the fleet has to collect an additional 30 and 50 tonnes from mills 1 and 4 on "Day 6", respectively.

a: A feasible solution for a week

\begin{tabular}{|l|c|c|c|c|c|c|c|}
\hline & $\begin{array}{c}\text { Olive } \\
\text { mill } 1\end{array}$ & $\begin{array}{c}\text { Olive } \\
\text { mill } 2\end{array}$ & $\begin{array}{c}\text { Olive } \\
\text { mill } 3\end{array}$ & $\begin{array}{c}\text { Olive } \\
\text { mill } 4\end{array}$ & $\begin{array}{c}\text { Olive } \\
\text { mill } 5\end{array}$ & Total & $\begin{array}{c}\text { Served } \\
\text { Olive mills }\end{array}$ \\
\hline Day 1 & 15 & 30 & 20 & 25 & 10 & 100 & $1,2,3,4,5$ \\
\hline Day 2 & 15 & 30 & 20 & 25 & 10 & 100 & $1,2,3,4,5$ \\
\hline Day 3 & 15 & 30 & 20 & 25 & 10 & 100 & $1,2,3,4,5$ \\
\hline Day 4 & 15 & 30 & 20 & 25 & 10 & 100 & $1,2,3,4,5$ \\
\hline Day 5 & 15 & 30 & 20 & 25 & 10 & 100 & $1,2,3,4,5$ \\
\hline Day 6 & 15 & 30 & 20 & 25 & 10 & 100 & $1,2,3,4,5$ \\
\hline Day 7 & 15 & 30 & 20 & 25 & 10 & 100 & $1,2,3,4,5$ \\
\hline Total & 105 & 210 & 140 & 175 & 70 & 700 & $1,2,3,4,5$ \\
\hline
\end{tabular}

b: A destroyed solution for a week

\begin{tabular}{|l|c|c|c|c|c|c|c|}
\hline & $\begin{array}{c}\text { Olive } \\
\text { mill } 1\end{array}$ & $\begin{array}{c}\text { Olive } \\
\text { mill } 2\end{array}$ & $\begin{array}{c}\text { Olive } \\
\text { mill } 3\end{array}$ & $\begin{array}{c}\text { Olive } \\
\text { mill } 4\end{array}$ & $\begin{array}{c}\text { Olive } \\
\text { mill } 5\end{array}$ & Total & $\begin{array}{c}\text { Served } \\
\text { Olive mills }\end{array}$ \\
\hline Day 1 & 15 & 30 & 20 & 25 & 10 & 100 & $1,2,3,4,5$ \\
\hline Day 2 & $\bigcirc$ & 30 & 20 & $\bigcirc$ & 10 & $\mathbf{6 0}$ & $\mathbf{2 , 3 , 5}$ \\
\hline Day 3 & 15 & 30 & 20 & 25 & 10 & 100 & $1,2,3,4,5$ \\
\hline Day 4 & 15 & 30 & 20 & 25 & 10 & 100 & $1,2,3,4,5$ \\
\hline Day 5 & 15 & 30 & 20 & 25 & 10 & 100 & $1,2,3,4,5$ \\
\hline Day 6 & 15 & 30 & 20 & 25 & 10 & 100 & $1,2,3,4,5$ \\
\hline Day 7 & 15 & 30 & 20 & 25 & 10 & 100 & $1,2,3,4,5$ \\
\hline Total & $\mathbf{9 0}$ & 210 & 140 & 150 & 70 & $\mathbf{6 6 0}$ & $1,2,3,4,5$ \\
\hline
\end{tabular}

c: A repaired solution for a week

\begin{tabular}{|l|c|c|c|c|c|c|c|}
\hline & $\begin{array}{c}\text { Olive } \\
\text { mill } 1\end{array}$ & $\begin{array}{c}\text { Olive } \\
\text { mill } 2\end{array}$ & $\begin{array}{c}\text { Olive } \\
\text { mill } 3\end{array}$ & $\begin{array}{c}\text { Olive } \\
\text { mill } 4\end{array}$ & $\begin{array}{c}\text { Olive } \\
\text { mill } 5\end{array}$ & Total & $\begin{array}{c}\text { Served } \\
\text { Olive mills }\end{array}$ \\
\hline Day 1 & 15 & 30 & 20 & 25 & 10 & 100 & $1,2,3,4,5$ \\
\hline Day 2 & & 30 & 20 & & 10 & 60 & $2,3,5$ \\
\hline Day 3 & 15 & 30 & 20 & 25 & 10 & 100 & $1,2,3,4,5$ \\
\hline Day 4 & 15 & 30 & 20 & 25 & 10 & 100 & $1,2,3,4,5$ \\
\hline Day 5 & 15 & 30 & 20 & 25 & 10 & 100 & $1,2,3,4,5$ \\
\hline Day 6 & $\mathbf{3 0}$ & 30 & 20 & $\mathbf{5 0}$ & 10 & $\mathbf{1 4 0}$ & $1,2,3,4,5$ \\
\hline Day 7 & 15 & 30 & 20 & 25 & 10 & 100 & $1,2,3,4,5$ \\
\hline Total & $\mathbf{1 0 5}$ & 210 & 140 & $\mathbf{1 7 5}$ & 70 & $\mathbf{7 0 0}$ & $1,2,3,4,5$ \\
\hline
\end{tabular}

Figure 3: An illustration of the multiperiodic removal and insertion procedures 
- Version 3: MP-ALNS 3 : The third version, MP-ALNS 3 , is similar to MP-ALNS 2 . It only differs by the criterion by wherein removal and insertion days are selected, as opposed to a random selection. The criterion used is one of increasing the capacity utilization of vehicles. To this end, we first calculate the average daily capacity utilisation rate $\Pi(h)$, expressed as the ratio of the total daily OMWW over the total capacity of vehicles used on day $h \in \mathcal{H}$, as follows:

$$
\Pi(h)=\frac{\sum_{i \in \mathcal{N}_{c}} \sum_{j \in \mathcal{N}_{0}} q_{i} x_{i j}^{h}}{\sum_{k \in \mathcal{N}_{0}} \sum_{j \in \mathcal{N}_{c}} x_{k j}^{h} Q} .
$$

We then select the removal day as $h_{r}=\underset{h \in \mathcal{H}}{\operatorname{argmin}} \Pi(h)$ and the insertion day as $h_{i}=\underset{h \in \mathcal{H} \backslash\left\{h_{r}\right\}}{\operatorname{argmin}} \Pi(h)$.

\section{A Case Study}

In this section, we present an application of the proposed method on a case study arising in one of the major olive oil producing countries. Turkey accounts for $9 \%$ of the total amount of olives and $5.6 \%$ of olive production in the world, where approximately 150 thousand tonnes of olive oil are produced every year. Aydın is a city in Turkey, which holds about $17 \%$ of Turkey's olive tree fields. The city ranks first in the country with $26 \%$ of the total olive growth and is the second city in terms of the total olive oil production in the country, with a proportion of $29 \%$. Recent agricultural policies introduced in Turkey have resulted in a $12 \%$ increase in olive tree fields and a $28 \%$ increase in the number of olive trees over the past few years. This growth is expected to result in a similar increase in the amount of OMWW produced, which will bring with it some of the challenges as was outlined in the Introduction. In this section, we will first describe the case study in more detail, including the input data used, and then present the associated results obtained with the metaheuristic algorithm.

\section{Input Data}

There are currently 155 olive mills operating in Aydın, some of which are located within very close proximity to one another. To reduce the complexity of the problem, some of the closely located mills have been clustered into one, resulting in 92 mill locations altogether. This required a calculation of a distance matrix of $92^{2} / 2-92=4140$ entries where the distances were obtained from an online map. Furthermore, we have identified seven potential locations for OMWW treatment plants in Aydın through liaising with industry, some of which are based in existing industrial zones. The $92 \times 7=644$ additional distances between each 
mill location and a potential facility location were also drawn from the same online map. Figure 4 shows the location of Aydın in the country, as well as with the olive oil mills (indicated by the small yellow circles) and the potential locations for the treatment plans (indicated by the large red circles).

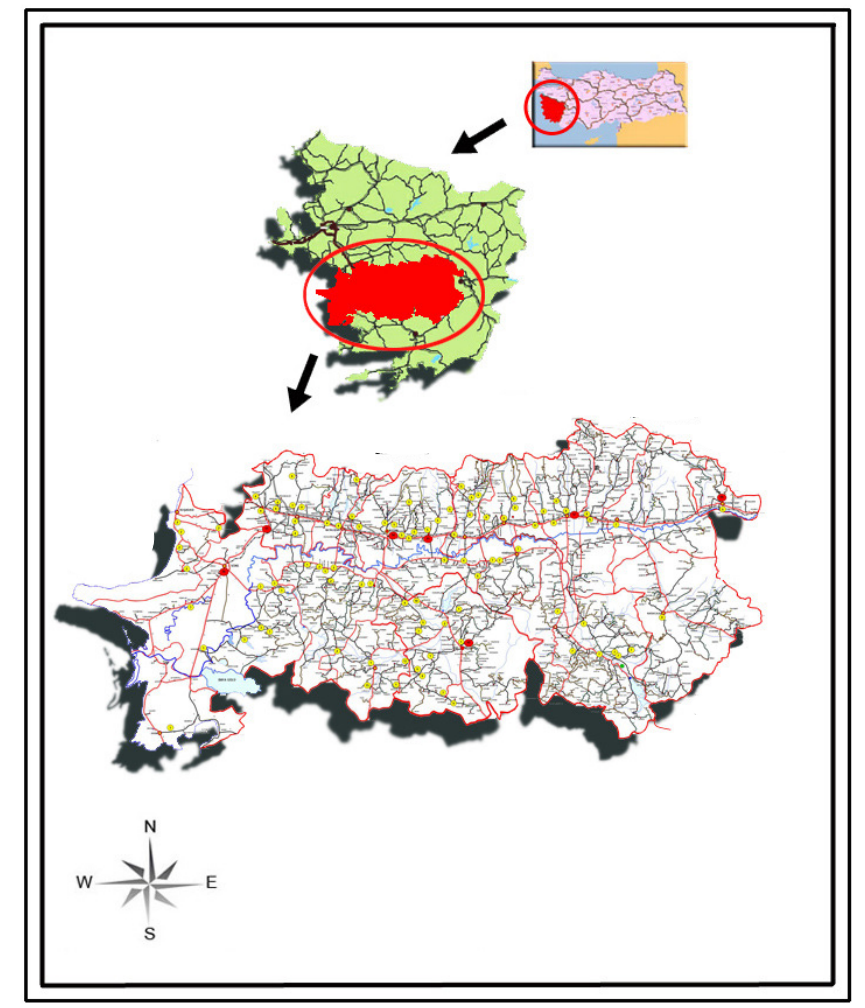

Figure 4: A map of Aydın and the existing olive oil mills

Another set of input data relates to the maximum operating capacity of each of the 92 olive oil mill locations, which was collected from the olive oil mills operating in the city and is summarised in Figure 5. This figure shows the number of mills operating in different capacity bands, and indicates that a great majority of the mills have a capacity to be able to operate up to 100 tonnes every day. The actual amount of olives processed per day, however, is variable, as it depends on the amount of olives brought in by local farms. Although our study uses average figures for planning purposes, we will explore the changes in these parameters through a sensitivity analysis presented in the following sections.

The remaining data required have been acquired through liaising with the relevant practitioners. One set of these data relates to the efficiency with which the factories operate, which was found to be $40 \%$ on average. In other words, the amount of olives brought to the mills is such that it only requires each mill, on average, to operate at $40 \%$ of its capacity. Using the fact that modern methods produce about one litre of OMWW per $1 \mathrm{~kg}$ of milled olives (Rinaldi et al., 2003), the daily output of OMWW for each mill was also estimated. 


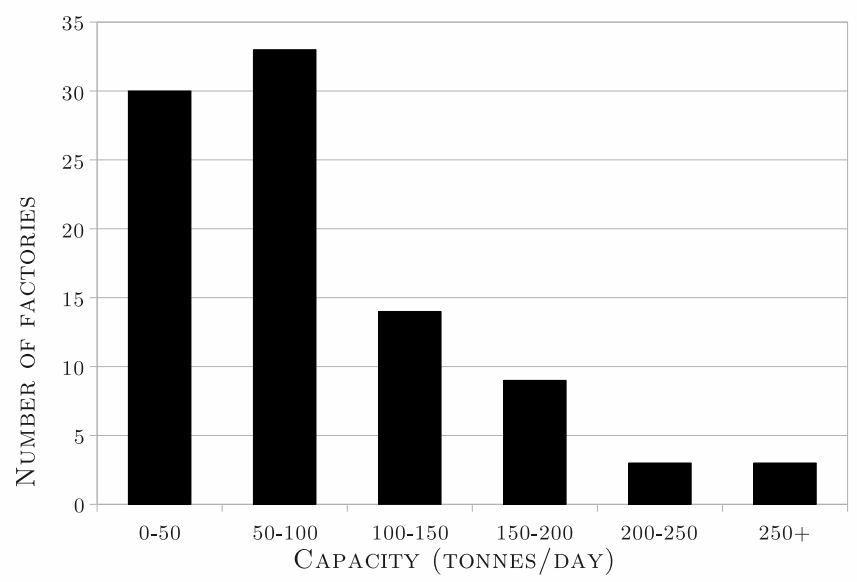

Figure 5: A summary of the operating capacity for olive mills in Aydın

Olive production is known to exhibit an alternate bearing structure with high yield in one year followed by low yield in the subsequent year. The former is sometimes referred to as an "on" year and the latter as an "off" year (Al-Shdiefat and Qrunfleh, 2008). Olive mills in Aydın only operate for three months in "on" years and two months in "off" years. This implies a $(90+60) / 2=75$ day "year" used in our calculations.

We assume that OMWW will be transported by dedicated vehicles, which are normally tanker trucks (see, e.g., Diamantis et al., 2015) with a capacity of 32-tonnes and for which the unit cost of transportation is set to $\delta=€ 0.14 /$ tonne-km (using $£ 0.12 /$ tonne-km from Carter and Troyano-Cuturi (2010)). The treatment facilities themselves can be established in three levels $\mathcal{S}=\{1,2,3\}$ of capacities, operating with: (i) $b_{1}=$ $100 \mathrm{~m}^{3}$ /day at a cost of approximately $g_{k}^{1}=€ 450,000$ for all $k \in \mathcal{N}_{0}$, (ii) $b_{2}=200 \mathrm{~m}^{3} /$ day at a cost of approximately $g_{k}^{2}=€ 700,000$ for all $k \in \mathcal{N}_{0}$, and (iii) $b_{3}=500 \mathrm{~m}^{3} /$ day at a cost of approximately $g_{k}^{3}=€ 1 \mathrm{M}$ for all $k \in \mathcal{N}_{0}$.

\section{Computational Experiments and Analyses}

We now present the results of our computational experiments. The MP-ALNS was implemented in C++. All experiments were conducted on a server with one gigabyte RAM and an Intel Xeon 2.6 GHz processor. The parameter values used in the MP-ALNS are provided in Table 1 which were found using a meta-calibration procedure. For the MP-ALNS, ten separate runs are performed for each instance, the best one of which is reported.

The analysis of the proposed approach for the case study has considered fixed parameters, such as transportation costs or amounts of OMWW to be processed weekly. In our experiments, we will explore the 
Table 1: Parameters used in the MP-ALNS

\begin{tabular}{ll}
\hline Description & Typical values \\
\hline Total number of iterations ( $\varpi)$ & 5000 \\
Number of iterations for roulette wheel (see Koç et al., 2015) & 100 \\
Roulette wheel parameter (see Koç et al., 2015) & 0.1 \\
Penalty parameter for a new global solution (see Koç et al., 2015) & 1 \\
Penalty parameter for a better solution than current (see Koç et al., 2015) & 0 \\
Penalty parameter for a worse solution than current (see Koç et al., 2015) & 5 \\
Startup temperature parameter $\left(T_{0}\right)$ & 100 \\
Cooling parameter $(\chi)$ & 0.999 \\
Lower limit of removable nodes $\left(b_{l}\right)$ & $10 \%$ of $\left|\mathcal{N}_{c}\right|$ \\
Upper limit of removable nodes $\left(b_{u}\right)$ & $30 \%$ of $\left|\mathcal{N}_{c}\right|$ \\
First shaw parameter (see Koç et al., 2015) & 0.5 \\
Second shaw parameter (see Koç et al., 2015) & 0.15 \\
Third shaw parameter (see Koç et al., 2015) & 0.25 \\
Noise parameter (see Koç et al., 2015) & 0.1 \\
\hline
\end{tabular}

effects of possible changes in the values of the main parameters on the total cost of the system. In particular, we will investigate whether the MP-ALNS variations (MP-ALNS $1, M P-\mathrm{ALNS}_{2}$ and MP-ALNS 3 ) yield cost-effective solutions when there is growth in the values of these parameters. The aim of the computational experiments is fourfold, and in particular to empirically calculate the effect of any changes in: 1) the length of time that the proposed model is to be used for, 2) method components, 3) the unit transportation cost and the amount of olive production, and 4) the vehicle capacity.

\section{The effect of the length of the planning horizon}

One important consideration in the experiments is the way in which facility set-up costs, which relates to a strategic decision, and the costs of transportation, which is either tactical (if the plans run from 6-12 months) or operational (in the event that they are changed weekly or monthly), are combined. To be able to compare the two different cost components, we bring the facility set-up costs down to daily costs through a simple multiple year appraisal approach. To this end, we consider a planning horizon of length 10, 20 and 30 years over which the proposed operations are expected run.

The results are presented in Table where the first column shows the version of the algorithm used, the second displays the decisions on the number of facilities at each level. In particular, we use the notation $\left(\alpha_{1}, \alpha_{2}, \alpha_{3}\right)$, where $\alpha_{1}, \alpha_{2}$ and $\alpha_{3}$ correspond to the number of facilities opened at capacity levels 1, 2 and 3. The remaining columns show the facility cost $(€)$, transportation cost $(€)$, total cost $(€)$ and the computational running time (in seconds), for each version of the algorithm.

Table 2 shows that for all appraisal variations, the MP-ALNS 3 provide better solutions as compared to the 
Table 2: The effect of changing the length of the planning horizon on total cost

\begin{tabular}{|c|c|c|c|c|c|}
\hline \multirow[t]{2}{*}{ Version } & \multicolumn{5}{|c|}{ 10-year appraisal } \\
\hline & $\begin{array}{l}\text { Number of } \\
\text { facilities }\end{array}$ & $\begin{array}{l}\text { Facility } \\
\operatorname{cost~}(€)\end{array}$ & $\begin{array}{l}\text { Transportation } \\
\text { cost }(€)\end{array}$ & $\begin{array}{l}\text { Total } \\
\text { cost }(€)\end{array}$ & $\begin{array}{l}\text { Time } \\
\text { (s) }\end{array}$ \\
\hline MP-ALNS $_{1}$ & $(4,2,0)$ & 3933.00 & 1605.16 & 5538.16 & 188.62 \\
\hline MP-ALNS $_{2}$ & $(4,2,0)$ & 3933.00 & 1578.60 & 5511.60 & 216.75 \\
\hline \multirow[t]{3}{*}{ 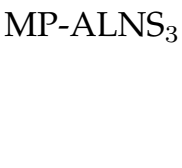 } & $(4,2,0)$ & 3933.00 & 1523.82 & 5456.82 & 227.20 \\
\hline & \multicolumn{5}{|c|}{ 20-year appraisal } \\
\hline & $\begin{array}{l}\text { Number of } \\
\text { facilities }\end{array}$ & $\begin{array}{l}\text { Facility } \\
\text { cost }(€)\end{array}$ & $\begin{array}{l}\text { Transportation } \\
\text { cost }(€)\end{array}$ & $\begin{array}{l}\text { Total } \\
\text { cost }(€)\end{array}$ & $\begin{array}{l}\text { Time } \\
\text { (s) }\end{array}$ \\
\hline MP-ALNS $_{1}$ & $(3,3,0)$ & 2132.00 & 1493.93 & 3625.93 & 182.71 \\
\hline${\mathrm{MP}-\mathrm{ALNS}_{2}}$ & $(4,1,1)$ & 1966.00 & 1585.56 & 3551.56 & 234.90 \\
\hline \multirow[t]{3}{*}{${\mathrm{MP}-\mathrm{ALNS}_{3}}_{3}$} & $(4,2,0)$ & 1966.00 & 1506.57 & 3472.57 & 236.55 \\
\hline & \multicolumn{5}{|c|}{ 30-year appraisal } \\
\hline & $\begin{array}{l}\text { Number of } \\
\text { facilities }\end{array}$ & $\begin{array}{l}\text { Facility } \\
\operatorname{cost}(€)\end{array}$ & $\begin{array}{l}\text { Transportation } \\
\text { cost }(€)\end{array}$ & $\begin{array}{l}\text { Total } \\
\text { cost }(€)\end{array}$ & $\begin{array}{l}\text { Time } \\
\text { (s) }\end{array}$ \\
\hline MP-ALNS ${ }_{1}$ & $(4,1,1)$ & 1422.00 & 1584.09 & 3006.09 & 208.21 \\
\hline MP-ALNS $_{2}$ & $(4,1,1)$ & 1311.00 & 1658.38 & 2969.38 & 213.22 \\
\hline${\mathrm{MP}-\mathrm{ALNS}_{3}}_{3}$ & $(4,2,0)$ & 1311.00 & 1509.91 & 2820.91 & 247.02 \\
\hline
\end{tabular}

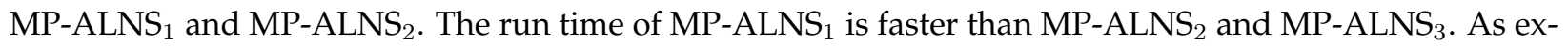
pected, we see a decrease in the total facility and total costs from a 10- to a 30-year appraisal. Transportation costs are similar for which MP-ALNS ${ }_{3}$ resulted in $€ 1532.82, € 1506.67$ and $€ 1509.91$ for $10-, 20$ - and 30-year appraisals, respectively. These results show that transportation costs do not follow a similar order of magnitutude as facility costs. Furthermore, it can be seen that changing the appraisal length does not have an impact on the number of opened treatment facilities. In particular, four facilities at capacity level 1 and two facilities at capacity level 2 are opened for all three year appraisals with this version of the algorithm.

Table 3 shows the percent deviation of the total cost of a given planning horizon from another one. For example, the second column $\operatorname{Dev}_{10 / 20}$ represents the percent deviation of the total cost of a 10-year appraisal from that of 20-year.

Table 3: Comparisons of different appraisals

\begin{tabular}{l|ll|ll|ll}
\hline \multirow{2}{*}{ Version } & \multicolumn{2}{|c|}{ 10-year appraisal } & \multicolumn{2}{c|}{ 20-year appraisal } & \multicolumn{2}{c}{ 30-year appraisal } \\
\cline { 2 - 7 } & $\operatorname{Dev}_{10 / 20}$ & $\operatorname{Dev}_{10 / 30}$ & $\operatorname{Dev}_{20 / 10}$ & $\operatorname{Dev}_{20 / 30}$ & $\operatorname{Dev}_{30 / 10}$ & $\operatorname{Dev}_{30 / 20}$ \\
\hline MP-ALNS $_{1}$ & 52.74 & 84.23 & -34.53 & 20.62 & -45.72 & -17.09 \\
MP-ALNS $_{2}$ & 55.19 & 85.61 & -35.56 & 19.61 & -46.12 & -16.39 \\
MP-ALNS $_{3}$ & 57.14 & 93.44 & -36.36 & 23.10 & -48.30 & -18.77 \\
\hline
\end{tabular}

Table 3 provides several interesting insights. It is clear that 10-year appraisal has the highest total cost. For example, the MP-ALNS 3 finds that the total cost of a 10 -year appraisal is $57.14 \%$ and $93.44 \%$ higher than 20- and 30-year appraisals, respectively. On the other hand, if we use a 30-year appraisal, the total costs are decreased by $48.30 \%$ and $18.77 \%$ when compared with 10 - and 20 -year appraisals, respectively. As 
expected, the total cost of 20-year appraisal stays in the middle between the other appraisals. The total cost in this case is $36.36 \%$ lower and $23.10 \%$ higher than 10 - and 30 -year appraisals, respectively.

In the rest of the experiments, we will assume a 10-year appraisal as the parameters tested in the following sections relate more to a shorter planning horizon.

\section{Sensitivity analysis of method components}

This section compares three versions of the MP-ALNS, the details of which can be found in Table 4 . We conducted a set of experiments to investigate the MP-ALNS ${ }_{1}, \mathrm{MP}-\mathrm{ALNS}_{2}$ and MP-ALNS 3 while ensuring that they are run under a common computational time limit. The column $\operatorname{Dev}_{M P-A L N S_{3}}$ shows the percent deviation of the total cost of MP-ALNS or MP-ALNS $_{2}$ from the total cost of MP-ALNS . $_{3}$

Table 4: Sensitivity analysis of the MP-ALNS components

\begin{tabular}{lllllll}
\hline Version & 10-year appraisal & & & & \\
\hline & $\begin{array}{l}\text { Opened } \\
\text { facilities }\end{array}$ & $\begin{array}{l}\text { Facility } \\
\text { cost }\end{array}$ & $\begin{array}{l}\text { Transportation } \\
\text { cost }\end{array}$ & $\begin{array}{l}\text { Total } \\
\text { cost }\end{array}$ & $\operatorname{Dev}_{M P-A L N S_{3}}$ & $\begin{array}{l}\text { Time } \\
\text { (s) }\end{array}$ \\
\hline MP-ALNS $_{1}$ & $(4,2,0)$ & 3933.00 & 1602.16 & 5535.16 & 1.23 & 200.00 \\
MP-ALNS $_{2}$ & $(4,2,0)$ & 3933.00 & 1590.60 & 5523.60 & 1.03 & 200.00 \\
MP-ALNS $_{3}$ & $(4,2,0)$ & 3933.00 & 1533.82 & 5466.82 & - & 200.00 \\
\hline
\end{tabular}

These results clearly indicate that MP-ALNS 3 has a better performance as compared to MP-ALNS ${ }_{1}$ and MP-ALNS ${ }_{2}$ when they are given the same computational time. In particular, under a 200 second time limit, MP-ALNS 3 provides $1.23 \%$ and $1.03 \%$ better solutions than MP-ALNS 1 and MP-ALNS ${ }_{2}$, respectively.

\section{The effect of unit transportation costs and the amount of olive production}

The transportation cost was initially set at $\delta=0.14 € /$ tonne-km (Carter and Troyano-Cuturi, 2010). In this section, we first gradually increase this value from $10 \%$ to $40 \%$ in increments of $10 \%$ and compare with the base case where there is no change $(0 \%)$ in this parameter. The results of these analyses are presented in Table 5 where each row presents the percentage increase in the total cost, by using three versions of the algorithm. The column Total cost $(€)$ is self-explanatory and the column Dev $(\%)$ is the percentage change of cost compared with the base case.

Table 5 shows that changes in unit transportation cost has a direct effect on the total cost, but the increase is relatively mild. For example, looking at $\mathrm{MP}-\mathrm{ALNS}_{3}$, the total costs increases by $4.19 \%, 5.71 \%, 7.30 \%$ and $10.57 \%$ when the unit transportation costs increase by $10 \%, 20 \%, 30 \%$ and $40 \%$, respectively. 
Table 5: The effect of variations in unit transportation costs

\begin{tabular}{|c|c|c|c|c|c|c|c|c|c|}
\hline \multirow[t]{3}{*}{ Version } & \multicolumn{9}{|c|}{ Changes in unit transportation cost } \\
\hline & \multicolumn{2}{|c|}{$+10 \%$} & \multicolumn{2}{|c|}{$+20 \%$} & \multicolumn{2}{|l|}{$+30 \%$} & \multicolumn{2}{|l|}{$+40 \%$} & \multirow{2}{*}{$\begin{array}{l}0 \% \\
\text { Total } \\
\text { cost (€) }\end{array}$} \\
\hline & $\begin{array}{l}\text { Total } \\
\text { cost }(€)\end{array}$ & $\operatorname{Dev}(\%)$ & $\begin{array}{l}\text { Total } \\
\operatorname{cost}(€)\end{array}$ & Dev (\%) & $\begin{array}{l}\text { Total } \\
\operatorname{cost}(€)\end{array}$ & $\operatorname{Dev}(\%)$ & $\begin{array}{l}\text { Total } \\
\text { cost }(€)\end{array}$ & $\operatorname{Dev}(\%)$ & \\
\hline MP-ALNS $_{1}$ & 5831.49 & 5.03 & 5844.85 & 5.25 & 6255.25 & 11.46 & 6402.37 & 13.50 & 5538.16 \\
\hline${\mathrm{MP}-\mathrm{ALNS}_{2}}_{2}$ & 5719.38 & 3.63 & 5806.51 & 5.08 & 5950.92 & 7.38 & 6102.02 & 9.68 & 5511.60 \\
\hline${\mathrm{MP}-\mathrm{ALNS}_{3}}_{4}$ & 5695.66 & 4.19 & 5787.11 & 5.71 & 5886.45 & 7.30 & 6101.48 & 10.57 & 5456.82 \\
\hline
\end{tabular}

We now analyse the impact of the growing the amount of olive production and subsequently the resulting OMWW, on the overall cost. In particular, we increase the amount of OMWW to be collected from each olive oil mill from $10 \%$ to $40 \%$ in increments of $10 \%$ and compare with the base case ( $0 \%$ change). The results of this analysis are presented in Table 6, using the same format of Table 5.

Table 6: The effect of variations in the amount of olive production

\begin{tabular}{|c|c|c|c|c|c|c|c|c|c|}
\hline \multirow[t]{3}{*}{ Version } & \multicolumn{9}{|c|}{ Changes in the amount of olive production } \\
\hline & \multicolumn{2}{|c|}{$+10 \%$} & \multicolumn{2}{|c|}{$+20 \%$} & \multicolumn{2}{|l|}{$+30 \%$} & \multicolumn{2}{|l|}{$+40 \%$} & $0 \%$ \\
\hline & $\begin{array}{l}\text { Total } \\
\operatorname{cost}(€)\end{array}$ & $\operatorname{Dev}(\%)$ & $\begin{array}{l}\text { Total } \\
\text { cost }(€)\end{array}$ & $\operatorname{Dev}(\%)$ & $\begin{array}{l}\text { Total } \\
\operatorname{cost}(€)\end{array}$ & $\operatorname{Dev}(\%)$ & $\begin{array}{l}\text { Total } \\
\operatorname{cost}(€)\end{array}$ & $\operatorname{Dev}(\%)$ & $\begin{array}{l}\text { Total } \\
\operatorname{cost}(€)\end{array}$ \\
\hline MP-ALNS $_{1}$ & 6162.42 & 10.13 & 7936.76 & 30.22 & 7268.9 & 23.81 & 8937.12 & 38.03 & 5538.16 \\
\hline $\mathrm{MP}-\mathrm{ALNS}_{2}$ & 6139.59 & 10.23 & 6630.04 & 16.87 & 7198.93 & 23.44 & 8303.01 & 33.62 & 5511.60 \\
\hline${\mathrm{MP}-\mathrm{ALNS}_{3}}_{3}$ & 6076.57 & 10.20 & 6297.27 & 13.35 & 7188.26 & 24.09 & 8065.43 & 32.34 & 5456.82 \\
\hline
\end{tabular}

It is obvious from Table 6 that the MP-ALNS 3 once again yields a lower total cost relative to the other versions of the MP-ALNS. When we increase the amount of olive production by $10 \%, 20 \%, 30 \%$ and $40 \%$, the total costs are increased by $10.20 \%, 13.35 \%, 24.09 \%$ and $32.34 \%$, respectively. Our results suggest that any increase in the olive production which directly effects the amount of OMWW also increase the total cost as expected, but, unlike the transportation costs, the changes are only weakly proportional.

We now investigate the integrated effect of variations in unit transportation costs and in the amount of olive production. To do so, we decrease the amount of OMWW to be collected from each olive oil mill by $40 \%$ and $20 \%$, and increase by $20 \%$ and $40 \%$. At the same time, we decrease the transportation cost by $40 \%$ and $20 \%$, and increase by $20 \%$ and $40 \%$. We compare the results with the base case ( $0 \%$ change) and presented them in Table 7.

Table 7 shows that when we decrease the amount of olive production and unit transportation cost by $40 \%$ and $20 \%$, the total cost are decreased by $-61.84 \%$ and $-22.25 \%$, respectively. When we increase both of them by $20 \%$ and $40 \%$, the total cost are increased by $17.50 \%$ and $37.71 \%$, respectively. This results indicate that any decrease or increase in the olive production and in unit transportation cost directly effects the total cost. 
Table 7: The effect of variations in unit transportation costs and in the amount of olive production

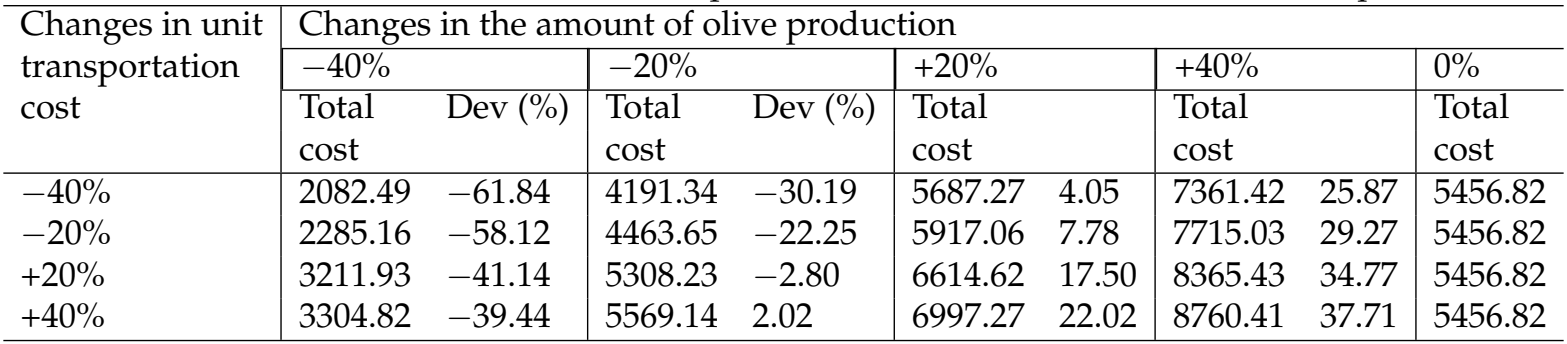

\section{The effect of the vehicle capacity}

We now analyse the impact of the vehicle capacity on the total costs and on the vehicle capacity utilisation. To do so, we conduct several analyses by increasing the vehicle capacity by $10 \%, 20 \%, 30 \%$ and $40 \%$. In Table 8 , we present the results where we compare the total cost with the base case $(0 \%$ change) and report the percent deviation results under column Dev (\%). In Table 9, the column capacity utilisation (\%) displays the average percentage capacity utilisation of the vehicle fleet, which is calculated as 100 (the total amount of OMWW collected from all olive oil mills)/(the total capacity of all used vehicles).

Table 8: The effect of variations in the vehicle capacity

\begin{tabular}{|c|c|c|c|c|c|c|c|c|c|}
\hline \multirow[t]{3}{*}{ Version } & \multicolumn{9}{|c|}{ Changes in the vehicle capacity } \\
\hline & \multicolumn{2}{|c|}{$+10 \%$} & \multicolumn{2}{|c|}{$+20 \%$} & \multicolumn{2}{|l|}{$+30 \%$} & \multicolumn{2}{|l|}{$+40 \%$} & \multirow{2}{*}{$\begin{array}{l}0 \% \\
\text { Total } \\
\text { cost (€) }\end{array}$} \\
\hline & $\begin{array}{l}\text { Total } \\
\operatorname{cost}(€)\end{array}$ & $\operatorname{Dev}(\%)$ & $\begin{array}{l}\text { Total } \\
\operatorname{cost}(€)\end{array}$ & $\operatorname{Dev}(\%)$ & $\begin{array}{l}\text { Total } \\
\text { cost }(€)\end{array}$ & $\operatorname{Dev}(\%)$ & $\begin{array}{l}\text { Total } \\
\operatorname{cost}(€)\end{array}$ & $\operatorname{Dev}(\%)$ & \\
\hline MP-ALNS $_{1}$ & 5510.36 & -0.50 & 5498.21 & -0.73 & 5504.96 & -0.60 & 5471.88 & -1.21 & 5538.16 \\
\hline${\mathrm{MP}-\mathrm{ALNS}_{2}}_{2}$ & 5494.94 & -0.30 & 5383.32 & -2.38 & 5474.94 & -0.67 & 5445.44 & -1.21 & 5511.60 \\
\hline${\mathrm{MP}-\mathrm{ALNS}_{3}}$ & 5452.31 & -0.08 & 5286.79 & -3.22 & 5218.78 & -4.56 & 5160.27 & -5.75 & 5456.82 \\
\hline
\end{tabular}

Table 9: Vehicle capacity utilizations

\begin{tabular}{|c|c|c|c|c|c|}
\hline \multirow[t]{3}{*}{ Version } & \multicolumn{5}{|c|}{ Changes in the vehicle capacity } \\
\hline & $0 \%$ & $10 \%$ & $20 \%$ & $30 \%$ & $40 \%$ \\
\hline & $\begin{array}{l}\text { Capacity } \\
\text { utilisation (\%) }\end{array}$ & $\begin{array}{l}\text { Capacity } \\
\text { utilisation (\%) }\end{array}$ & $\begin{array}{l}\text { Capacity } \\
\text { utilisation (\%) }\end{array}$ & $\begin{array}{l}\text { Capacity } \\
\text { utilisation (\%) }\end{array}$ & $\begin{array}{l}\text { Capacity } \\
\text { utilisation (\%) }\end{array}$ \\
\hline MP-ALNS_1 & 74.21 & 77.81 & 76.41 & 72.41 & 70.12 \\
\hline MP-ALNS_2 & 72.13 & 75.41 & 74.13 & 74.58 & 42.36 \\
\hline MP-ALNS_3 & 81.64 & 86.54 & 83.65 & 81.39 & 82.64 \\
\hline
\end{tabular}

The results shown in Table 8 indicate that the MP-ALNS ${ }_{3}$ once again provides better solutions than MP$\mathrm{ALNS}_{1}$ and MP-ALNS ${ }_{2}$. Our results shows that the total costs are decreased by $0.08 \%, 3.22 \%, 4.56 \%$ and $5.75 \%$ when we increase the vehicle capacity by $10 \%, 20 \%, 30 \%$ and $40 \%$, respectively. It is interesting that a $10 \%$ increase in capacity decreases the total cost only marginally. These results indicate that for the considered problem parameters it is better to use vehicles with a larger capacity, such as 45 -tonne vehicles, which implies around a $40 \%$ increase in vehicle capacity. As for the capacity utilisation of vehicle capacities, 
Table 9 indicates that the best results are obtained by MP-ALNS 3 . The utilisations are $86.54 \%, 83.65 \%$, $81.39 \%$ and $82.64 \%$ when we increase the vehicle capacity by $10 \%, 20 \%, 30 \%$ and $40 \%$, respectively. With the current vehicle capacity of 32 -tonnes, the utilisation is at $81.64 \%$. These results generally indicate that increases in capacities do not play a significant role in the utilisation of the vehicles.

\section{Industrial and practical perspectives}

In this section, we look at the economical viability of the proposed system using the results presented above. Whilst it is difficult to come up with accurate estimates of the costs given that the proposed system is not yet implemented, it will still be possible to give an indication of how the costs of the proposed system compare against some current practices. For example, Azbar et al. (2004) provide cost estimates of treatment schemes for a three-phase olive oil mill, with an estimated output of $5000 \mathrm{~m}^{3}$ under a 10-year appraisal. According to their estimates, the total cost of treatment through natural evaporation is $€ 0.65-1.31$ per cubic meter of OMWW, notwithstanding the odor and fly problems mentioned earlier. The estimated treatment cost, however, is reported by the same study to rise to $€ 10.43$ if evaporation was to be forced through mechanical interventions.

Using the costs presented in Table 2, and considering that the data set here comprised 155 mills, it is easy to calculate that the daily cost of the proposed system under a 10-year appraisal is approximately $€ 35$. A similar calculation for 20 and 30-year appraisals would result in $€ 24 /$ day and $€ 18 /$ day, respectively. Depending on the volume of OMWW generated per day, these costs would compare favourably with those reported above for the use of lagoons, and increase the likelihood of take-up of such a collective system by the industry. Any further external funding made available will also imply further reduction of these costs. However, it is not only the cost alone that would drive the take-up, but the health and safety benefits of such a system would bring.

Our findings are supported by the recommendations made by some of the earlier EU projects funded and completed in this area, which is to use central treatment facilities to significantly reduced the required capital and operational costs, as opposed to each mill installing its own treatment facility (see, e.g., project MINOS completed between 2001-2004 ${ }^{1}$ ).

\footnotetext{
${ }^{1}$ http://ec.europa.eu/environment/life/project/Projects/PDF/LIFE00_ENV_GR_000671_LAYMAN.pdf
} 


\section{Conclusions}

This paper introduced, formally defined and studied the joint problem of the location of facilities and routing decisions arising in the treatment of OMWW that is based on the collective use of ultrafiltration facilities by olive oil mills. We have described a Multiperiodic-Adaptive Large Neighbourhood Search (MP-ALNS) metaheuristic to solve the problem. The MP-ALNS establishes the number and location of the facilities to be set up, and plans the weekly transportation activities for a number of vehicles to visit the olive oil mills, to collect OMWW, and to deliver to the treatment facilities. We presented results of computational experiments and analyses conducted in order to gain an understanding into the parameters of the problem using a case study from the city of Aydın in Turkey. We have also provided several managerial insights. Our method, to the best of our knowledge, is a first in addressing the important and challenging issue of dealing with the operationalisation of collection of OMWW. The problem of OMWW is a significant one faced in Aydin and indeed elsewhere in many other olive oil-producing countries. It is hoped that the method proposed in this paper will contribute to the ongoing efforts in overcoming this problem.

\section{Acknowledgements}

The authors gratefully acknowledge funding provided by the Southampton Business School at the University of Southampton, the Scientific and Technological Research Council of Turkey (TÜBITTAK) and British Council in carrying out this research. Thanks are due to the Associate Editor and two anonymous referees for their valuable comments.

\section{References}

Akdemir, E. O., Ozer, A. 2008. Application of a statistical technique for olive oil mill wastewater treatment using ultrafiltration process. Separation and Purification Technology 62, 222-227.

Albareda-Sambola, M., 2015. Location-routing and location-arc routing problems. In Laporte, G., Nickel, S., Saldanha da Gama, F. (Eds.), Location Science. (pp. 399-418). Springer, Berlin-Heidelberg.

Albareda-Sambola, M., Fernández, E., Nickel, S., 2012. Multiperiod location-routing with decoupled time scales. European Journal of Operational Research 217, 248-258.

Al-Shdiefat, S. M., Qrunfleh, M. Q., 2008. Alternate bearing of the olive (olea europaea L.) as related to endogenous hormonal content. Jordan Journal of Agricultural Sciences 4, 12-24.

Alumur, S., Kara, B. Y., 2007. A new model for the hazardous waste location-routing problem. Computers \& Operations Research 34, 1406-1423. 
Axelrad, G., Feinerman, E., 2009. Regional planning of wastewater reuse for irrigation and river rehabilitation. Journal of Agricultural Economics 60, 105-131.

Azbar, N., Bayram, A., Filibeli, A., Muezzinoglu, A., Sengul, F., Ozer, A., 2004. A review of waste management options in olive oil production. Critical Reviews in Environmental Science and Technology 34, 209-247.

Benjamin, A. M., Beasley, J. E., 2010. Metaheuristics for the waste collection vehicle routing problem with time windows, driver rest period and multiple disposal facilities. Computers \& Operations Research 37, 2270-2280.

Carter, J., Troyano-Cuturi, K., 2010. Capsule Pipelines for Aggregate Transport: Economics. http: //www3.imperial.ac.uk/earthscienceandengineering/research/energyenvmodmin/ capsule/economics (accessed 02.07.2015).

Diamantis, V., Erguder, T.H., Aivasidis, A., Verstraete, W., Voudrias, E., 2013. Wastewater disposal to landfill-sites: A synergistic solution for centralized management of olive mill wastewater and enhanced production of landfill gas. Journal of Environmental Management 128, 427-434.

Drexl, M., Schneider, M., 2015. A survey of variants and extensions of the location-routing problem. European Journal of Operational Research 241, 283-308.

FAO, 2015. Food and Agriculture Organization of the United Nations. http: / /www . fao.org (accessed 10.05.2015).

Giannikos, I., 1998. A multiobjective programming model for locating treatment sites and routing hazardous wastes. European Journal of Operational Research 104, 333-342.

Hemmelmayr, V. C., Doerner, K. F., Hartl, R. F., 2009. A variable neighborhood search heuristic for periodic routing problems. European Journal of Operational Research 195, 791-802.

Kim, B.-I., Kim, S., Sahoo, S., 2006. Waste collection vehicle routing problem with time windows. Computers \& Operations Research 33, 3624-3642.

Koç, Ç., Bektaş, T., Jabali, O., Laporte, G., 2015. A hybrid evolutionary algorithm for heterogeneous fleet vehicle routing problems. Computers \& Operations Research 64, 11-27.

Koç, Ç., Bektaş, T., Jabali, O., Laporte, G., 2016. The fleet size and mix location-routing problem with time windows: Formulations and a heuristic algorithm. European Journal of Operational Research 248, 33-51.

Laporte, G., 1988. Location-routing problems. In: Golden, B. L., Assad, A. A. (Eds.), Vehicle Routing: Methods and Studies. (pp. 163-198). North-Holland, Amsterdam.

Laporte, G., Ropke, S., Vidal, T. 2014. Heuristics for the vehicle routing problem, in P. Toth and D. Vigo, (Eds.), Vehicle Routing: Problems, Methods and Applications. (pp. 87-116). MOS-SIAM Series in Optimization, Philadelphia.

Libralato, G., Ghirardini, A. V., Avezzú, 2012. To centralise or to decentralise: An overview of the most reent trends in wastewater treatment management. Journal of environmental management 94, 61-68. 
Mahmoud, M. Janssen, M., Haboub, N., Nassour, A., Lennartz, B., 2010. The impact of olive mill wastewater application on flow and transport properties in soils. Soil \& Tillage Research 107, 36-41.

Nagy, G., Salhi, S., 2007. Location-routing: Issues, models and methods. European Journal of Operational Research 177, 649-672.

Paredes, M. J., Moreno, E., Ramos-Cormenzana, A., Martinez, J., 1987. Characteristics of soil after pollution with wastewaters from olive oil extraction plants. Chemosphere 16, 1557-1564.

Pisinger, D., Ropke, S., 2007. A general heuristic for vehicle routing problems. Computers \& Operations Research 34, 2403-2435.

Prodhon, C. Prins, C., 2014. A survey of recent research on location-routing problems. European Journal of Operational Research 238, 1-17.

Rinaldi, M., Rana, G., Introna, M., 2003. Olive-mill wastewater spreading in southern Italy: effects on a durum wheat crop. Field Crops Research 84, 319-326.

Roig, A., Cayuela, M. L., Sánchez-Monedero, M. A., 2006. An overview on olive mill wastes and their valorisation methods. Waste Management 26, 960-969.

Ropke, S., Pisinger, D., 2006a. An adaptive large neighborhood search heuristic for the pickup and delivery problem with time windows. Transportation Science 40, 455-472.

Ropke, S., Pisinger, D., 2006b. A unified heuristic for a large class of vehicle routing problems with backhauls. European Journal of Operational Research 171, 750-775.

Samanlioglu, F., 2013. A multi-objective mathematical model for the industrial hazardous waste locationrouting problem. European Journal of Operational Research 226, 332-340.

Von Boventer, E., 1961. The relationship between transportation costs and location rent in transportation problems. Journal of Regional Science 3, 27-40.

Zografros, K. G., Samara, S., 1989. Combined location-routing model for hazardous waste transportation and disposal. Transportation Research Record 1245, 52-59. 